\title{
VIOLÊNCIA NO NORTE PIONEIRO DO ESTADO DO PARANÁ: HOMICÍDIOS E APREENSÃO DE DROGAS
}

\author{
Violence in the Pioneer North of State of Paraná: homicide and drug seizure \\ Violencia en el Norte Pionero del Estado de Paraná: homicidio y incautación de drogas
}

Pedro Henrique Carnevalli Fernandes ${ }^{1}$ http://orcid.org/0000-0001-7542-7912

1 Doutor em Geografia. Professor Adjunto na Universidade Estadual do Norte do Paraná-UENP- Brasil;
pedrofernandes@uenp.edu.br

\section{Resumo}

A segurança pública se converteu em um tema no Brasil devido, principalmente, à violência. No campo acadêmico, é visível uma ampliação dos estudos acerca da violência. Por isso, este artigo tem como objetivo principal refletir acerca da violência no Norte Pioneiro do Estado do Paraná a partir dos homicídios e da apreensão de drogas. Os procedimentos metodológicos foram: levantamento de referenciais teóricos acerca da violência; levantamento de dados de homicídios e de apreensão de drogas no Norte Pioneiro do Paraná; e, por fim, elaboração de produções cartográficas e da redação final. A violência possui diferentes abordagens, porém poucos estudos em pequenas cidades. No Norte Pioneiro, os dados revelam uma epidemia de violência.

Palavras-chave: Geografia da Violência. Pequenas Cidades. Violência.

\begin{abstract}
Public security has become a topic in Brazil due mainly to violence. In the academic field, a broadening of studies on violence is visible. Therefore, this paper aims to reflect on violence in the Pioneer North of the State of Paraná from homicides and drug seizures. The methodological procedures were survey of theoretical references about violence; survey of homicide and drug seizure data in the Pioneer North of Paraná; and, finally, elaboration of cartographic productions and the final writing. Violence has different approaches, but few studies related to small towns. In the Pioneer North, the data reveal an epidemic of violence.
\end{abstract}

Keywords: Geography of Violence. Small towns. Violence.

\section{Resumen}

La seguridad pública se ha convertido en un tema en Brasil debido, principalmente, a la violencia. En el campo académico, es visible una ampliación de los estudios sobre violencia. Por lo tanto, este artículo tiene como objetivo reflexionar sobre la violencia en el Norte Pioneer del Estado de Paraná por los homicidios y las incautaciones de drogas. Los procedimientos metodológicos fueron: encuesta de referencias teóricas sobre violencia; los datos de homicidios recogida y de incautación de drogas en Norte Pioneer de Paraná; y, finalmente, la preparación de la producción cartográfica y el proyecto final. La violencia tiene diferentes enfoques, pero pocos estudios en las ciudades pequeñas. En el Norte Pioneer, los datos revelan una epidemia. 
Palabras clave: Geografía de la Violencia. Ciudades pequeñas. Violencia.

\section{Introdução}

A segurança pública se converteu em um dos principais temas da agenda brasileira. Logo, acredita-se que os projetos governamentais relacionados à segurança pública, caso não ocorram a partir da proposta de inclusão de todos e pautados em uma perspectiva antiviolência, fracassarão. No campo acadêmico, é visível uma ampliação dos estudos acerca da violência, sendo que na Ciência Geográfica estão inseridos na chamada Geografia da Violência.

A Constituição Federal de 1988 aborda no Título V (Da defesa do Estado e das Instituições Democráticas) - Capítulo III - a segurança pública, definindo, no artigo 144, que a "segurança pública, dever do Estado, direito e responsabilidade de todos, é exercida para a preservação da ordem pública e da incolumidade das pessoas e do patrimônio" (BRASIL, 1998, p. 79). Assim, segurança pública corresponde à segurança do público, da coletividade/cidadãos e do patrimônio, seja em espaços públicos, como as ruas, praças e edifícios públicos, seja nos espaços privados de residência, trabalho e lazer.

Para Souza (2008, p. 150), “idealmente, a segurança pública é um conjunto de ações, medidas e intervenções, em diferentes domínios (...) que deve ir construindo as condições para uma segurança maior e para a redução dos riscos”. Assim, para ele, a segurança se tornou um "paradigma do governo" em que se criminalizam determinados grupos da sociedade e o medo da violência e do crime são utilizados como pretextos para um controle social, além de fomentar a "indústria da segurança" e a "indústria da mídia". Portanto, o Estado atual, impulsionado pela globalização e pela lógica capitalista, não protege a sociedade e, pior, prejudica a liberdade.

O objetivo principal deste artigo é refletir acerca da violência no Norte Pioneiro do Estado do Paraná. Para isso, tem-se como objetivos específicos: avançar teoricamente no debate sobre a violência, compreender os dados de homicídios no Norte Pioneiro do Estado do Paraná e entender os dados de apreensão de drogas no Norte Pioneiro do Estado do Paraná. 
Os procedimentos metodológicos foram: levantamento de referenciais teóricos acerca da violência; levantamento de dados de homicídios e de apreensão de drogas nos municípios do Norte Pioneiro do Paraná; e, por fim, elaboração de produções cartográficas e da redação final. O recorte espacial da pesquisa é o Norte Pioneiro do Estado do Paraná (Mapa 1). Essa região é compreendida, segundo o IBGE (2008; 2010), por 46 municípios, correspondendo a uma área de aproximadamente 15 mil quilômetros quadrados (7,5\% do território paranaense) e a meio milhão de habitantes (5\% da população do Paraná). Todos os municípios da região são polarizados por uma pequena cidade.

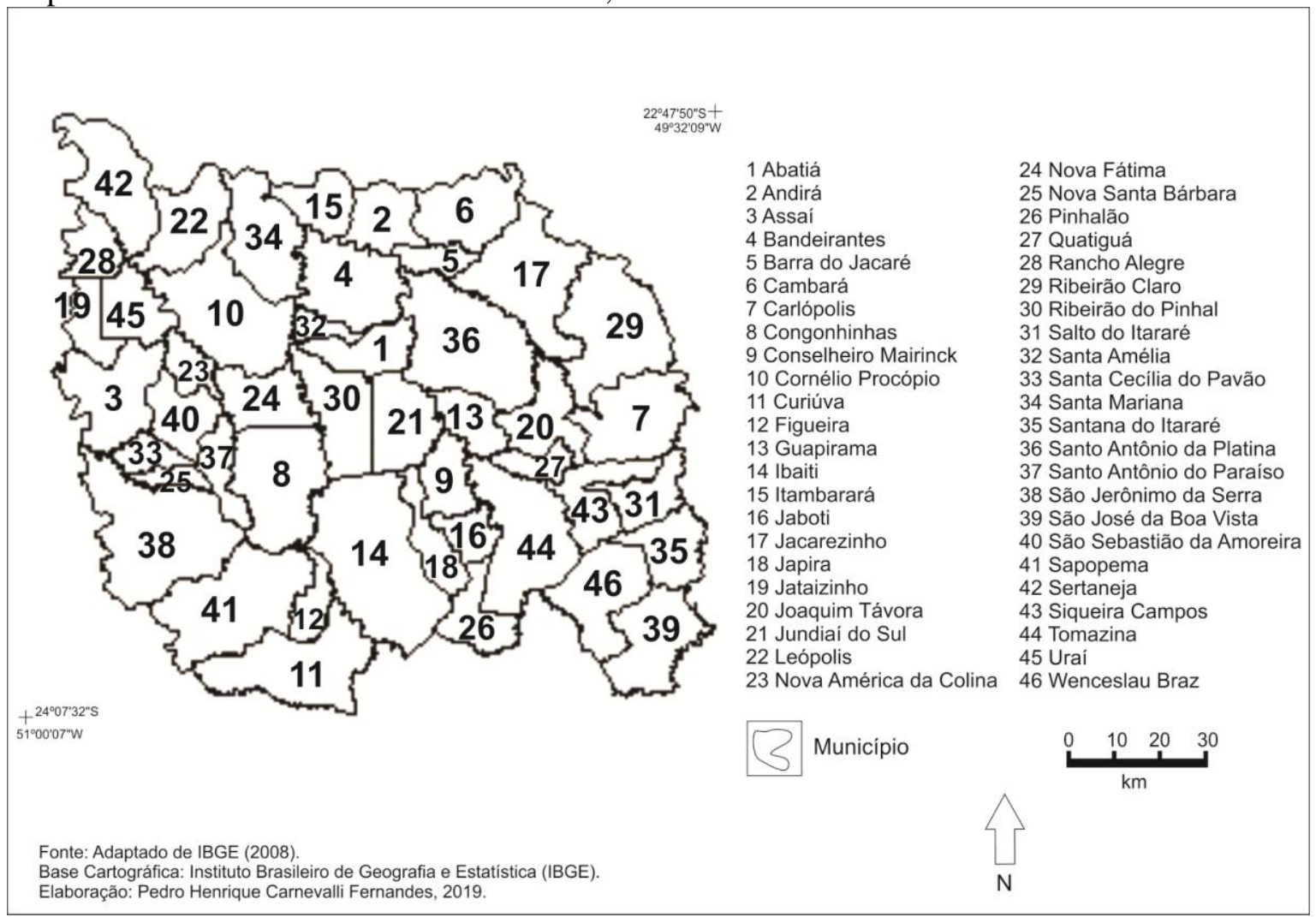

Fonte: Adaptado de IBGE (2008)

Nesse sentido, o artigo está estruturado da seguinte forma, além da introdução e das considerações finais: a segunda parte apresenta a base teórica da violência, destacando as múltiplas possibilidades de estudos acerca desse tema; a terceira parte aborda os resultados acerca dos dados de homicídios na região Norte Pioneiro do Estado do Paraná; e, finalmente, a quarta destaca os resultados dos dados de apreensão de drogas na região Norte Pioneiro do Estado do Paraná. 


\section{A violência}

Desde o início do século XXI, se tem percebido um aumento, quase que como um discurso de cunho universal, de comentários e ocorrências acerca da violência. Por isso, é fundamental que a academia debata o assunto de forma teórica - avançando no entendimento desse conceito - e de forma empírica - apresentando as realidades, tentando compreender as semelhanças e as diferenças da materialização desse fenômeno.

Os fervorosos embates sobre a temática causam divergências entre os pesquisadores. Assim, mais do que buscar méritos nesse debate, busca-se sistematizar a questão da violência. Apesar disso, na grande maioria dos trabalhos acadêmicos acerca da temática, independentemente da linha teórica do autor, os espaços contemplados são quase sempre os metropolitanos e/ou as cidades médias. Entretanto, alguns autores já visualizam o aumento da violência em espaços não metropolitanos, como as pequenas cidades e a área rural. Soma-se a isso, a dualidade de perspectivas: a abordagem material/concreta versus a abordagem imaterial/abstrata acerca da violência.

Violência é um termo se origina no latim “vis", que, inicialmente, significava "força". No século XVIII, o termo enfrentou uma evolução semântica e passou a ser entendido como "abuso de força". No século seguinte, tornou-se "força brutal para submeter alguém". Portanto, houve uma ampliação no campo semântico do termo violência. (RIFIOTIS, 1999; MAGALHÃES, 2009). Chaui (2006) colabora com essa interpretação: no plural, "vis" designa as partes sexuais do homem, as forças militares e, por extensão, as tropas.

Apesar dessa explicação semântica, Rifiotis (1999, p. 28) considera a violência como "uma palavra singular. Seu uso recorrente a tornou de tal modo familiar que parece desnecessário defini-la". Além disso, a sua utilização resulta de uma generalização de diversos fenômenos, que, quase sempre, são associados ao aspecto negativo. "Sua redução a uma forma singular e negativa pode ser entendida como expressão de uma percepção social marcada pela prevalência da atitude racional e pelo desprezo da dimensão nãoracional do comportamento" (RIFIOTIS, 1999, p. 28).

A violência não é recente e não ocorre apenas na sociedade atual. Segundo Teixeira e Porto (1998, p. 57), Michel Maffesoli, em 1978, já tratava a violência como "herança comum a todo e qualquer conjunto civilizatório, estruturando constantemente a vida em sociedade". Assim, no momento em que existiu a consolidação do dinamismo social, houve o conflito e o confronto, na qual a luta, fundamento de toda relação social, se 
manifestou em "instabilidade, espontaneidade, multiplicidade, desacordos e recusas" (TEIXEIRA; PORTO, 1998, p. 58).

Logo, a violência, tomando como base o discurso freudiano, é "um fenômeno inerente à condição humana" (MOREIRA; ABREU; OLIVEIRA, 2006, p. 629). Em outras palavras, a energia original que circula entre os sujeitos é a agressividade, sendo a sociabilidade um movimento secundário em relação à agressividade e como uma forma de driblar a condição humana de desamparo (MOREIRA; ABREU; OLIVEIRA, 2006). Assim, a sociedade teria "domesticado progressivamente sua violência (...), tornando-se uma civilização contra-a-violência" (CLASTRES, 1977 apud PEDRAZZINI, 2006, p. 20). Então, "os atos de barbárie cometidos desde então (...) seriam resíduos de épocas remotas, condenados a desaparecer com o progresso moral da humanidade" (PEDRAZZINI, 2006, p. 20).

Em contrapartida, a teoria frankliana alega que o homem tem causas para a violência, como psíquicas, emocionais, econômicas, entre outras (MOREIRA; ABREU; OLIVEIRA, 2006). Em outras palavras, o amor e o ódio são movidos por uma consciência intencional, portanto, encontram-se no campo do sentido, da razão e do logos; já a violência e a agressividade estão fora do logos (MOREIRA; ABREU; OLIVEIRA, 2006). O logos corresponde ao "elemento, meio, mediação e fim para os filósofos e para a vida urbana" (LEFEBVRE, 2001, p. 37-38).

Independentemente da corrente teórica, é fato, quase que incontestável, que "cinco séculos após o início da era de civilização, a violência segue intrinsecamente ligada a inúmeros atos humanos" (PEDRAZZINI, 2006, p. 20). Ela se converteu, assim, no ícone da modernidade em crise, sendo, “uma espécie de 'parte maldita', um 'resquício', um elo da corrente que nos prende no passado" (RIFIOTIS, 1999, p. 28) e/ou "uma espécie de patrimônio hereditário de (...) antepassados subumanos" (FRANKL, 1978, p. 65 apud MOREIRA; ABREU; OLIVEIRA, 2006, p. 630).

Entretanto, ela ganhou, claramente, maior proporção a partir da consolidação do capitalismo, se intensificando com o advento da globalização e com a busca desenfreada por poder (FERNANDES, 2017). Logo, ela é desterritorializada e onipresente, no sentido de não pertencer exclusivamente a um só espaço e não estar condicionada apenas a um grupo social. Igualmente, "os habitantes urbanos não conseguem mais distinguir as violências que os assustam, tampouco identificar o 'inimigo' ou o 'agressor'" 
(PEDRAZZINI, 2006, p. 100), sendo que "as cidades se transformaram em depósitos de problemas causados pela globalização" (BAUMAN, 2009, p. 32).

Souza (2008, p. 148) partilha dessa perspectiva: "sistema capitalista é, ele próprio, "criminógeno"”. Para o autor, o modelo social atual desperta um irrefreável desejo de consumo, ao mesmo tempo em que propicia somente a poucos a chance de satisfazê-los, coloca o "eu" muito acima do "nós" e o "ter" acima do "ser", privilegia a propriedade em detrimento da vida, engendra uma "indústria cultural" que se alimenta da criminalidade violenta e, por fim, facilita, por meio de desregulamentações, a lavagem de dinheiro, a corrupção e a injustiça social.

Partindo disso, para Pedrazzini (2006, p. 13), não se pode "limitar a discutir [apenas] a relação entre violência e urbanização, mas questionar como a globalização contribui atualmente para modificar sua natureza". Ainda de acordo com Pedrazzini (2006, p. 80), "as violências decorrem de formas contemporâneas de urbanização, pois são modos ditados pela globalização das relações econômicas determinadas por estratégias de dominação". Assim, o pânico que se instala nas cidades decorre da incerteza da globalização projetada (PEDRAZZINI, 2006), inclusive nas pequenas cidades (FERNANDES, 2017).

Teixeira e Porto (1998) acreditam que a consequência do processo de violência até os dias atuais, é tratada no sentido do poder e dividida em três espécies que visam fazer frente às formas de dominação: i) totalitária, no qual o seu resultado vem do monopólio de uma estrutura dominante, ou seja, do controle, da dominação e da coerção; ii) anômica, como resposta a violência totalitária e na tentativa de proteger o corpo social, como revoltas e manifestações contra as classe dominante; e, por fim, iii) banal, no qual ocorre uma passividade (ativa) da massa, mas se opondo ao poder, como ironias, comicidade, máscaras, grafites e pichações.

Para Viana (2002, p. 7), a violência é "uma relação social na qual um grupo ou indivíduo impõe algo a outro grupo ou indivíduo", ou seja, uma imposição, contra a vontade de quem sofre. Chaui (2006, p. 120-121) contribui alertando para a noção de margem na violência: "o problema consiste em saber onde está e qual é a margem que separa violência e não-violência". Entretanto, apesar da complexidade dessa abstração, ela a considera como um "ato brutal e antinatural de transgressão e violação da natureza, do direito, da justiça, das leis, dos costumes, do sagrado, das mulheres e dos mais fracos" (CHAUI, 2006, p. 120-121). 
Para Silva (2004), os estudos sobre a violência precisam contornar dois erros corriqueiros: a circularidade que envolve a confusão entre objeto e conceito de violência (ela, ao mesmo tempo, é o tema ou a questão a ser entendida e o fundamento de análise) e o reducionismo (homogeneização da violência e do espaço). É fundamental também considerar a existência de diferenças substanciais nas representações sociais de violência, ou seja, diferentes faixas etárias, gêneros e classes sociais veem e vivenciam o fenômeno (FERNANDES, 2017).

Goes $(1998 ; 2004 ; 2009)$ discute diversas ramificações relacionadas à violência, ao sentimento de insegurança urbana e a exclusão social, entre eles as rebeliões nos presídios paulistas, a imagem da polícia e como ela influencia nas relações de cidadania e de violência, a transição política no Brasil e seus desdobramentos, principalmente acerca das instituições de controle social, particularmente as penitenciárias, a presença das penitenciárias em cidades médias e pequenas e suas consequências na localidade e, por fim, o papel desempenhado pela mídia nesse fenômeno.

Souza (2008, p. 41) aborda a violência e a criminalidade como um "subproduto da 'dívida social' acumulada há gerações e gerações, sob a mediação de fatores institucionais (...) e culturais". Com relação ao primeiro, constitui a falência e inadequação intrínseca do sistema prisional, corrupção estrutural do aparato policia, entre outros elementos. Já com relação ao segundo, corresponde à ascensão de valores como consumismo e individualismo e hedonismo (SOUZA, 2008). Atrelado a isso, está o que Rodrigues (2002, p. 78) chama de "incapacidade das cidades [Estado] em atender os que nela vivem", onde se deveria refletir como as pessoas agiriam e se comportariam se tivessem infraestrutura, equipamentos e meios de consumo coletivos adequados.

A violência urbana é, em síntese, todo o exposto anteriormente, tendo como ocorrência o espaço urbano. Ela é definida, também, como a "violência derivada da organização do espaço urbano" (VIANA, 2002, p. 29), entre eles: a divisão social do trabalho, desigualdades sociais - emprego, moradia, transporte, educação, saúde, lazer, religião, conflitos sociais, ações do Estado, agentes valorizadores do solo urbano, estruturas físicas, entre outros.

Para Pedrazzini (2006, p. 69), “a violência, a insegurança, o pânico, as microguerras dos meninos de rua e os tráficos são alguns dos elementos duais mais evocados atualmente". Assim, na cidade contemporânea, à medida que a globalização divide-a em fragmentos antagônicos, transforma-a em um jogo de interesses. Logo, "o 
cenário urbano apresenta uma série de rupturas, fissuras, sinuosidades, conflitos, dissensões e distorções no campo social" (PEDRAZZINI, 2006, p. 79).

A violência urbana é, nos estudos de Silva (2004, p. 59), "uma forma de vida constituída pelo uso da força como princípio organizador das relações sociais". Ainda segundo ele, ela não se refere aos "comportamentos isolados, mas à sua articulação como uma ordem social". Ou seja, as cidades brasileiras vivem "um processo de consolidação de uma ordem social cujo principio de organização é o recurso universal à força" (SILVA, 2004, p. 62), ameaçando assim a segurança, em sua totalidade.

Assim, a Geografia e a Sociologia, como as demais Ciências Humanas, devem participar ativamente desse debate, pois a violência urbana passou a ser um elemento principal e condicionante nas relações e no modo de vida da população. Portanto, o desafio para as análises geográficas e sociológicas são a riqueza de ambiguidade da violência urbana perante a sociedade brasileira: "Expõe a vivência coletiva do caráter fragmentado da forma de vida urbana (...) e introduz a possibilidade de aprender um padrão de sociabilidade construído (pelos dominados) como violência urbana, a partir da incorporação crítica desta representação" (SILVA, 2004, p. 59).

O sociólogo apresenta, ainda, uma perspectiva relevante ao descrever a violência urbana como uma "expressão muito difundida e coletivamente aceita pelas populações urbanas para descrever cognitivamente e organizar o sentido subjetivo das práticas que envolvem o que legalmente se define como crime comum violenta" (SILVA, 2004, p. 58). O que o autor quer ressaltar é que se chegou a um ponto que determinadas situações de violência passaram a não comover, emocionar ou criar um sentimento de insatisfação, gerando uma verdadeira banalização da violência urbana.

A mídia tem parcela nisso, entretanto, outros fatores influenciam em tal aceitação, como o aumento da violência, a ausência do Estado em uma política menos severa de segurança, os desequilíbrio regionais, a má distribuição de renda, a impunidade das classes burguesas e dos detentores do poder - situação que Benevides (1983, p. 44) chama de "integrada à cultura brasileira" - e a ausência ou precariedade de serviços públicos como educação, saúde, lazer, saneamento, entre outros serviços.

Partindo disso, a sensação é de que, cada vez mais, as pessoas estão intolerantes umas com as outras. A intransigência, oriunda e justificada por qualquer motivo, compõe um conjunto totalitário inaceitável. Por isso, no que se refere ao âmbito das rotinas cotidianas, a violência urbana constrói "modelos de comportamento e experiências vividas 
não convencionais" (SILVA, 2004, p. 61), entre os quais se destacam o medo e, por conseguinte, a insegurança urbana. O medo configura-se como "um sentimento apreendido em perceber a existência de mecanismos de defesa recorrentes em casos de perigo" (GAVIRIA, 2008, p. 93).

Bauman (2007, p. 65) alerta que desde seu início, o Estado moderno foi confrontado com a tarefa de administrar o medo: "precisava tecer uma rede de proteção a partir do zero a fim de substituir a antiga, deixada de lado pela revolução moderna". Assim ele não o fez e, pior, com a ampliação da modernidade a proteção passou a se fragilizar ainda mais. Na sequência, as reflexões são decorrentes da materialização da violência no Norte Pioneiro do Paraná.

\section{Homicídios no Norte Pioneiro do Estado do Paraná}

No Norte do Estado do Paraná, a presença das pequenas cidades "é explicada pelo processo de formação socioespacial da região, ocorrido no contexto da economia cafeeira" (ENDLICH, 2006, p. 23), que, em determinado contexto histórico-geográfico do Paraná, foi a "mais dinâmica" (ENDLICH, 1998, p. 29), impulsionando a migração e o empreendimento dessa área. Logo, a agricultura cafeeira foi o principal motor das consolidações municipais nessa região, sendo que os primeiros relatos vinculados à presença do café são oriundos de 1860, em um momento em que "a ocupação ocorreu sem planejamento, de forma intensa e desordenada" (ENDLICH, 1998, p. 32). Entretanto, a partir de 1920, as políticas públicas estaduais incentivaram e permitiram concessões às empresas colonizadoras privadas capitalistas para a colonização (ENDLICH, 1998). Finalmente, no início da década de 1940, além das empresas privadas, houve a atuação de "empreendimentos estatais inspirados nas estratégias das referidas empresas" (ENDLICH, 1998, p. 32).

Depois, o declínio da economia cafeeira atuou contraditoriamente à situação inicial, ou seja, expulsando habitantes e influenciando no chamado declínio demográfico, que esvaziou, também, o aspecto funcional, particularmente quanto aos serviços e comércios (ENDLICH, 2006). Ambos os ciclos - crescimento e declínio demográfico -, em relativo curto período de tempo, modificaram o espaço regional e a estrutura urbana local dos municípios. 
A maioria das pessoas que se deslocaram para as cidades pequenas dessa região se depararam com a ausência ou a insuficiência de emprego e renda, moradia, serviços em gerais, como educação e saúde, entre outras necessidades, inclusive de oferta de produtos, lazer, serviços bancários, etc. (FERNANDES, 2017). Assim, as dinâmicas econômicas sofreram transformações e as cidades pequenas passaram a buscar novos papéis na rede urbana. O Mapa 2 apresenta as taxas de homicídios, entre 1996 e 2013, nos municípios que compõem o Norte Pioneiro do Paraná.

Mapa 2 - Norte Pioneiro do Estado do Paraná. Taxa de homicídio, por cem mil habitantes, 19962013

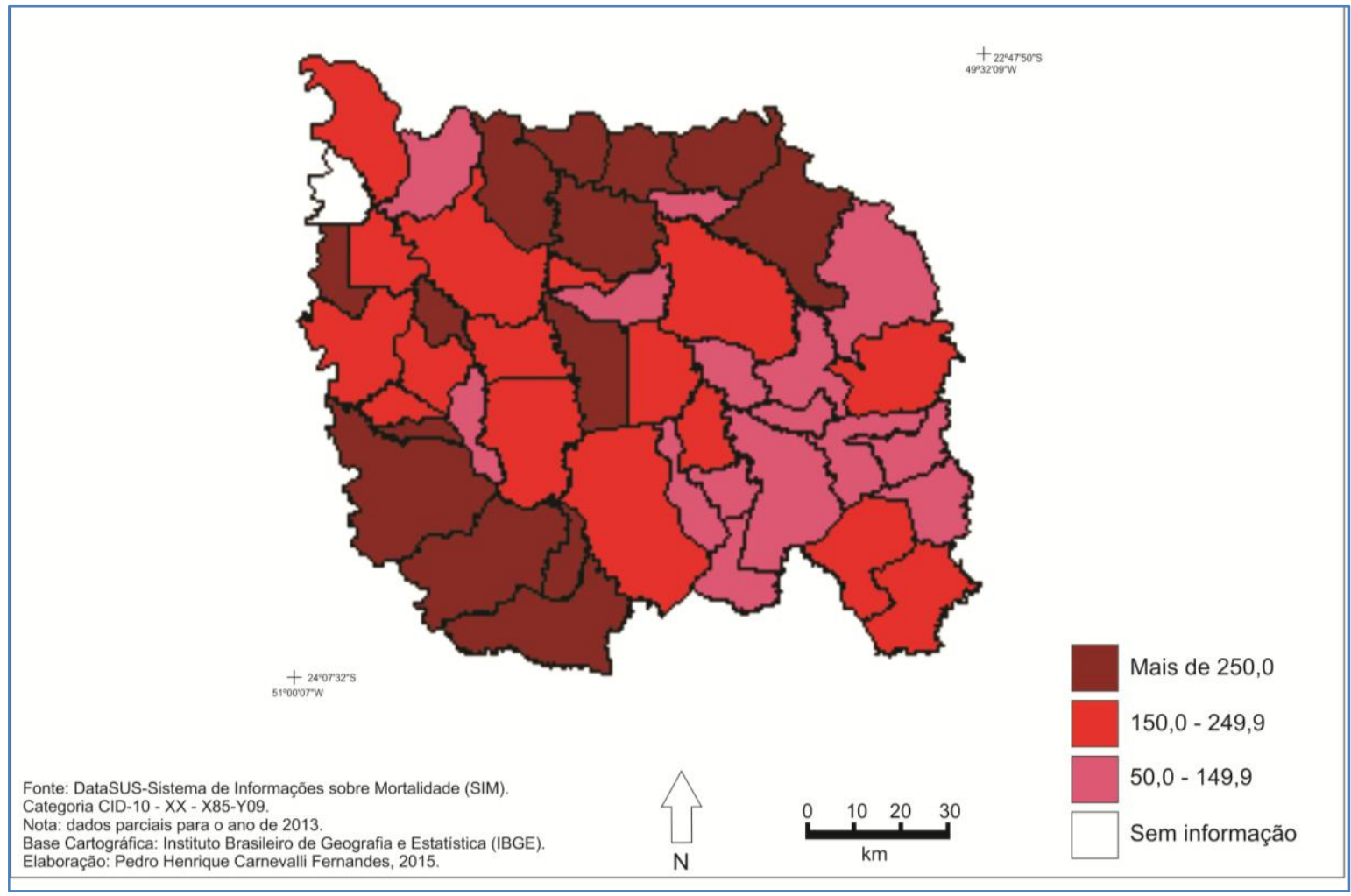

Fonte: Fernandes (2017)

Ele demonstra três movimentos de violência: no tom mais claro, municípios com as menores taxa de homicídio no período de 1996 a 2013 - o que não significa um estágio positivo quanto aos homicídios, mas, sim, uma realidade que já exige preocupação; no tom médio de coloração, municípios com taxas intermediárias de homicídio para o período de 1996 a 2013 - o que representa um estrato de transição entre o estágio alarmante e o estágio de epidemia (a partir de 180,0 de taxa); no tom mais escuro, municípios com as maiores taxas de homicídios no período de 1996 a 2013 da região - o que significa um estágio de epidemia de violência. 
Além disso, é possível constatar que, espacialmente, a porção Leste do Norte Pioneiro paranaense apresenta taxas de homicídios menores, possuindo oito entre os dez municípios com as menores taxas, com destaque para Tomazina e Japira - os municípios com as menores taxas da região. Por outro lado, as porções Norte e Sudoeste do Norte Pioneiro paranaense demonstram as maiores taxas da região, sendo que oito entre os dez municípios com as maiores taxas estão nesses recortes.

A Tabela 1 detalha os resultados do mapa anterior. Ela apresenta o ranking de taxa de homicídio, entre 1996 e 2013, dos municípios do Norte Pioneiro do Estado do Paraná. Nela foi inserida, para dimensionamento demográfico e para possibilitar aos interessados a realização do cálculo dos valores absolutos de homicídios em cada município, a população absoluta do município em 2010, segundo o último censo demográfico do IBGE. Os dados detalhados mostram que dois municípios apresentaram taxas superiores a 500 homicídios, por grupo de cem mil habitantes, entre 1996 e 2013: Itambaracá e Jataizinho. Segundo Fernandes (2017), a alta violência nesses dois municípios pode ser explicada pela faixa de fronteira para a realidade de Itambaracá, e pela lógica metropolitana para o contexto de Jataizinho.

Na sequência, outros dois municípios se destacam negativamente: Figueira e Nova Santa Bárbara, com taxas superiores a 400 homicídios, por grupo de cem mil habitantes, entre 1996 e 2013. Segundo Fernandes (2017), são casos que se explicam pela ausência ou insuficiência de serviços públicos de segurança.

Outros dez municípios possuem valores superiores a 250 homicídios, por grupo de cem mil habitantes, entre 1996 e 2013, vivenciando estágios epidêmicos de violência; entre eles, destaque para Nova América da Colina e Sapopema, os menores demograficamente, e para Bandeirantes e Jacarezinho, cidades relevantes na rede urbana regional e que possuem mais de trinta mil habitantes. Os dois municípios da região que possuem mais de quarenta mil habitantes, Cornélio Procópio e Santo Antônio da Platina, aparecem em $17^{\circ}$ e $15^{\circ}$, respectivamente, no ranking, com valores alarmantes de violência.

Tabela 1 - Norte Pioneiro do Paraná. Ranking de taxas de homicídios, por cem mil habitantes, 1996-2013

\begin{tabular}{clrr}
\hline Posição & Município & População absoluta (2010) & Taxa (96-13) \\
01 & Itambarará & 6.759 & 577,01 \\
02 & Jataizinho & 11.875 & 513,68 \\
03 & Figueira & 8.293 & 470,28 \\
04 & Nova Santa Bárbara & 3.908 & 460,59
\end{tabular}

V. 3, n. 3, 2019 http://periodicos2.uesb.br/index.php/geo

Este é um artigo de acesso aberto sob a licença Creative Commons da CC BY 


\begin{tabular}{|c|c|c|c|}
\hline 05 & Andirá & 20.610 & 388,16 \\
\hline 06 & Curiúva & 13.923 & 380,67 \\
\hline 07 & São Jerônimo da Serra & 11.337 & 352,83 \\
\hline 08 & Santa Mariana & 12.435 & 321,67 \\
\hline 09 & Nova América da Colina & 3.478 & 316,27 \\
\hline 10 & Jacarezinho & 39.121 & 283,74 \\
\hline 11 & Bandeirantes & 32.184 & 282,75 \\
\hline 12 & Sapopema & 6.736 & 282,07 \\
\hline 13 & Ribeirão do Pinhal & 13.524 & 266,19 \\
\hline 14 & Cambará & 23.886 & 259,57 \\
\hline 15 & Santo Antônio da Platina & 42.707 & 245,86 \\
\hline 16 & São José da Boa Vista & 6.511 & 245,74 \\
\hline 17 & Cornélio Procópio & 46.928 & 238,66 \\
\hline 18 & Ibaiti & 28.751 & 233,04 \\
\hline 19 & Assaí & 16.354 & 232,36 \\
\hline 20 & Uraí & 11.472 & 217,92 \\
\hline 21 & Congonhinhas & 8.279 & 217,42 \\
\hline 22 & Carlópolis & 13.706 & 204,29 \\
\hline 23 & Jundiaí do Sul & 3.433 & 203,90 \\
\hline 24 & São Sebastião da Amoreira & 8.626 & 197,08 \\
\hline 25 & Santa Cecília do Pavão & 3.646 & 191,99 \\
\hline 26 & Sertaneja & 5.817 & 189,10 \\
\hline 27 & Santa Amélia & 3.803 & 184,07 \\
\hline 28 & Nova Fátima & 8.147 & 171,84 \\
\hline 29 & Conselheiro Mairinck & 3.636 & 165,02 \\
\hline 30 & Wenceslau Braz & 19.298 & 155,46 \\
\hline 31 & Abatiá & 7.764 & 141,68 \\
\hline 32 & Pinhalão & 6.215 & 128,72 \\
\hline 33 & Quatiguá & 7.045 & 127,75 \\
\hline 34 & Japira & 4.903 & 122,37 \\
\hline 35 & Leópolis & 4.145 & 120,63 \\
\hline 36 & Salto do Itararé & 5.178 & 115,87 \\
\hline 37 & Siqueira Campos & 18.454 & 92,12 \\
\hline 38 & Ribeirão Claro & 10.678 & 84,29 \\
\hline 39 & Joaquim Távora & 10.736 & 83,83 \\
\hline 40 & Santo Antônio do Paraíso & 2.408 & 83,06 \\
\hline 41 & Guapirama & 3.891 & 77,10 \\
\hline 42 & Santana do Itararé & 5.249 & 76,20 \\
\hline 43 & Barra do Jacaré & 2.727 & 73,34 \\
\hline 44 & Jaboti & 4.902 & 61,20 \\
\hline 45 & Tomazina & 8.791 & 56,88 \\
\hline
\end{tabular}

Nota: O município de Rancho Alegre (3.955 habitantes) não disponibilizou os dados.

Fonte: Adaptado de Fernandes (2017).

No outro extremo dos resultados, nove municípios apresentam taxas de homicídios, por grupo de cem mil habitantes, entre 1996 e 2013, inferiores a cem, sendo que seis deles possuem menos de dez mil habitantes e quatro menos de cinco mil habitantes. O melhor 
resultado ficou com o município de Tomazina (8.791 habitantes), com taxa de 56,88 homicídios, por grupo de cem mil habitantes, entre 1996 e 2013. Na sequência, as reflexões transitam sobre a apreensão de drogas ilícitas no Norte Pioneiro do Estado do Paraná demonstrando seu alcance sobre as cidades e, por conseguinte, sua influência no fenômeno da violência.

\section{Apreensão de drogas no Norte Pioneiro do Estado do Paraná}

A apreensão de drogas também representa um indicador relevante no entendimento da violência. Segundo Fernandes (2017), o tráfico de drogas ilícitas é um dos principais fatores para a existência da violência nas cidades pequenas do Norte do Estado do Paraná, sobretudo na faixa de fronteira e na divisa do Paraná com o Estado de São Paulo. Além disso, Fernandes (2017) destaca o papel das rodovias e a influência da localização das bases de polícia rodoviária federal e de polícia rodoviária do Estado do Paraná nesse contexto, uma vez que representam, respectivamente, os principais locais de apreensão de drogas e os mais relevantes agentes no combate e nas ações/operações de apreensão de drogas.

Assim, o Mapa 3 apresenta as taxas de drogas apreendidas, em 2014, nos municípios que compõem o Norte Pioneiro do Paraná. É importante ressaltar que os resultados contemplam as seguintes drogas apreendidas: maconha, cocaína e crack. Ele demonstra quatro movimentos de apreensão de drogas: em branco, municípios sem apreensão de drogas; no tom mais claro, municípios com as menores taxa de apreensão de drogas, ou seja, menos de 0,6 quilogramas de drogas apreendidas por cem mil habitantes; no tom médio, municípios com taxas intermediárias de apreensão de drogas, ou seja, entre 0,7 e seis quilogramas de drogas apreendidas por cem mil habitantes; no tom mais escuro, municípios com as maiores taxas de apreensão de drogas, ou seja, com mais de 6,1 quilogramas de drogas apreendidas por cem mil habitantes.

Além disso, é possível constatar, espacialmente, duas porções bem definidas quanto à apreensão de drogas no Norte Pioneiro paranaense: a porção Norte da região apresenta as maiores taxas de apreensão, com exceções de Leópolis, Nova América da Colina, Santa Amélia e Barra do Jacaré - que não apresentam nenhuma apreensão de drogas no período. Já a porção Sul do Norte Pioneiro demonstra as menores taxas, incluindo o município de Congonhinhas, que ficou com o maior valor: 5,31 quilogramas de drogas apreendidas por 
cem mil habitantes, o que corresponde no município a menos de meio quilograma de drogas apreendidas em 2014.

Mapa 3 - Norte Pioneiro do Estado do Paraná. Taxa de drogas apreendidas, por cem mil habitantes, 2014

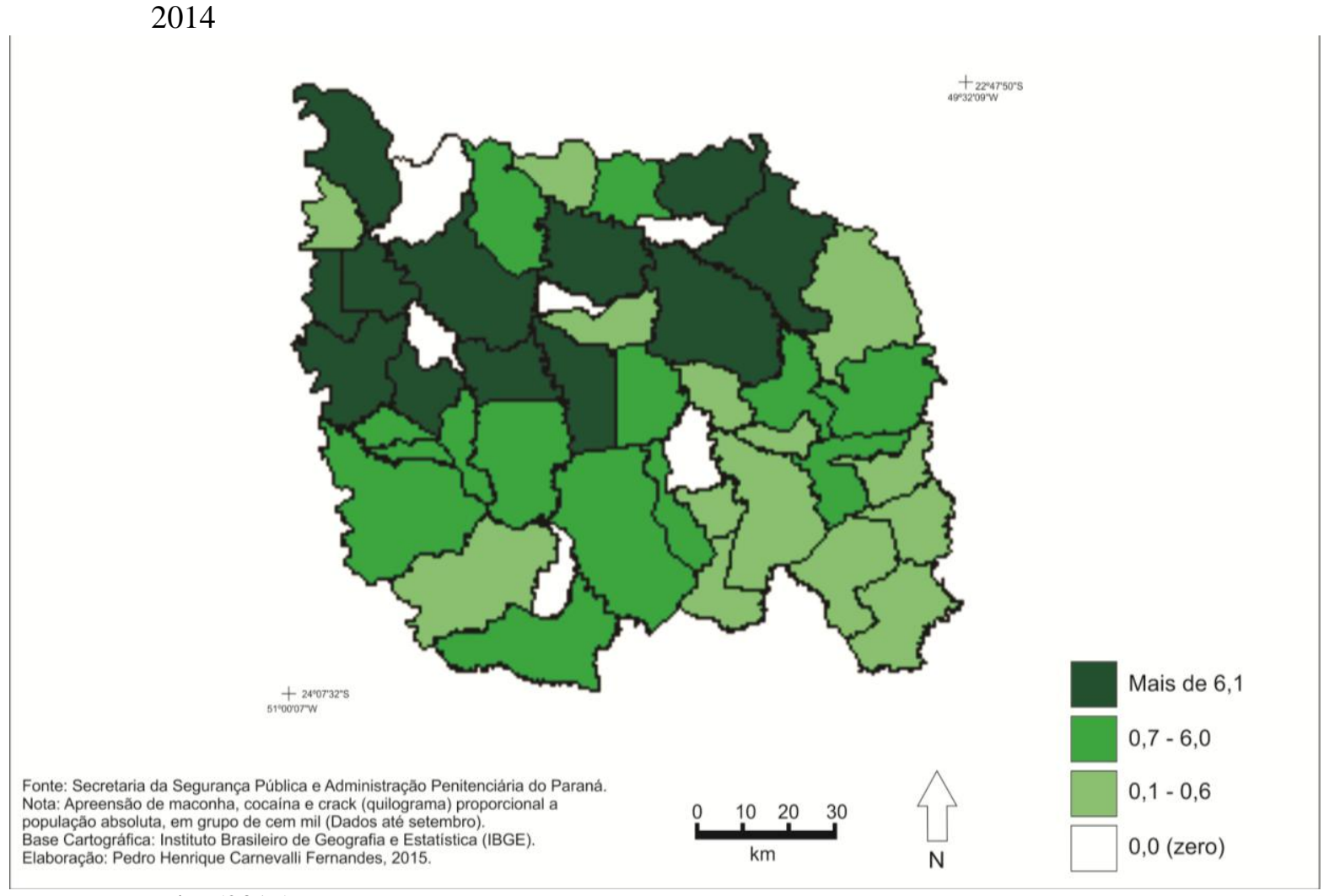

Fonte: Fernandes (2017)

A Tabela 2 apresenta o ranking de taxa de apreensão de drogas, em 2014, dos municípios do Norte Pioneiro do Paraná. Nela foi inserida, para dimensionamento demográfico e para possibilitar aos interessados a realização do cálculo dos valores absolutos de drogas apreendidas em cada município, a população absoluta do município em 2010, segundo o último censo do IBGE.

É possível constatar que os oito municípios com as maiores taxas destoam completamente dos demais e que o caso de Sertaneja é uma anomalia, uma vez que o município apresentou uma taxa de 3.412,24 quilogramas de drogas apreendidas por cem mil habitantes, em 2014, o que, na realidade de Sertaneja, corresponde a quase duzentos quilogramas de drogas apreendidas, sendo: 162,49 quilogramas de maconha, 18 quilograma de cocaína e 18 quilograma de crack. Isso se justifica pelo fato do município estar localizado estrategicamente na divisa entre os Estados do Paraná e de São Paulo e, decorrente disso, possuir, exatamente na divisa de Estado, na PR-323, uma base da Polícia 
Rodoviária Estadual no Posto Fiscal Charles Naufal, um dos postos que mais apreende drogas do Norte do Paraná.

Tabela 2. Norte Pioneiro do Estado do Paraná. Ranking de taxas de drogas apreendidas, por cem mil habitantes, 2014

\begin{tabular}{|c|c|c|c|}
\hline Posição & Município & População absoluta (2010) & Taxa (2014) \\
\hline 01 & Sertaneja & 5.817 & $3.412,24$ \\
\hline 02 & Santo Antônio da Platina & 42.707 & 279,42 \\
\hline 03 & Cornélio Procópio & 46.928 & 239,45 \\
\hline 04 & Jataizinho & 11.875 & 219,12 \\
\hline 05 & Nova Fátima & 8.147 & 216,15 \\
\hline 06 & São Sebastião da Amoreira & 8.626 & 138,19 \\
\hline 07 & Bandeirantes & 32.184 & 91,32 \\
\hline 08 & Ribeirão do Pinhal & 13.524 & 39,34 \\
\hline 09 & Cambará & 23.886 & 9,46 \\
\hline 10 & Jacarezinho & 39.121 & 7,87 \\
\hline 11 & Assaí & 16.354 & 7,64 \\
\hline 12 & Uraí & 11.472 & 6,80 \\
\hline 13 & Congonhinhas & 8.279 & 5,31 \\
\hline 14 & Santa Cecília do Pavão & 3.646 & 4,66 \\
\hline 15 & Andirá & 20.610 & 4,51 \\
\hline 16 & Siqueira Campos & 18.454 & 4,50 \\
\hline 17 & Santo Antônio do Paraíso & 2.408 & 4,15 \\
\hline 18 & Nova Santa Bárbara & 3.908 & 2,81 \\
\hline 19 & Ibaiti & 28.751 & 2,50 \\
\hline 20 & Santa Mariana & 12.435 & 2,01 \\
\hline 21 & Jundiaí do Sul & 3.433 & 1,46 \\
\hline 22 & Carlópolis & 13.706 & 1,31 \\
\hline 23 & São Jerônimo da Serra & 11.337 & 1,06 \\
\hline 24 & Japira & 4.903 & 1,02 \\
\hline 25 & Curiúva & 13.923 & 1,01 \\
\hline 26 & Joaquim Távora & 10.736 & 0,75 \\
\hline 27 & Sapopema & 6.736 & 0,59 \\
\hline 28 & Wenceslau Braz & 19.298 & 0,57 \\
\hline 29 & Guapirama & 3.891 & 0,51 \\
\hline 30 & Ribeirão Claro & 10.678 & 0,47 \\
\hline 31 & Jaboti & 4.902 & 0,41 \\
\hline 32 & São José da Boa Vista & 6.511 & 0,31 \\
\hline 33 & Itambarará & 6.759 & 0,30 \\
\hline 34 & Abatiá & 7.764 & 0,26 \\
\hline 35 & Rancho Alegre & 3.955 & 0,25 \\
\hline 36 & Salto do Itararé & 5.178 & 0,19 \\
\hline 37 & Santana do Itararé & 5.249 & 0,19 \\
\hline 38 & Pinhalão & 6.215 & 0,16 \\
\hline 39 & Quatiguá & 7.045 & 0,14 \\
\hline 40 & Tomazina & 8.791 & 0,11 \\
\hline
\end{tabular}

Nota: Os municípios de Barra do Jacaré (2.727 habitantes), Conselheiro Mairinck (3.636 habitantes), Figueira (8.293 habitantes), Leópolis (4.145 habitantes), Nova América da Colina (3.478 habitantes) e Santa Amélia (3.803 habitantes) não tiveram drogas apreendidas no período.

Fonte: Adaptado de Fernandes (2017). 
$\mathrm{Na}$ sequência, aparecem quatro municípios com valores superiores a duzentos quilogramas de drogas apreendidas por cem mil habitantes: Santo Antônio da Platina, Cornélio Procópio, Jataizinho e Nova Fátima. A explicação para o contexto deles é a presença de bases da polícia rodoviária federal em Jataizinho (o posto encontra-se no município de Ibiporã, na divisa com o município de Jataizinho, na BR-369), Cornélio Procópio (BR-369) e Santo Antônio da Platina (BR-153) e da polícia rodoviária estadual em Cornélio Procópio (PR-160) próximo da divisa de município com Nova Fátima.

O município de São Sebastião da Amoreira aparece na sexta posição e apresenta a realidade mais instigante, sobretudo por estar localizado em um trecho rodoviário de baixa circulação, por não possuir base rodoviária de polícia e por apresentar uma insuficiência de serviços públicos de segurança, sobretudo quanto às polícias militar e civil; por isso, esse caso demonstra uma relevante possibilidade de estudo futuro.

Os demais 32 municípios possuíram taxas de drogas apreendidas, em 2014, inferiores a dez quilogramas por cem mil habitantes, sendo que praticamente metade deles tiveram dados ainda menores: menos de um quilograma de drogas apreendidas por cem mil habitantes. Os dez municípios com menores taxas possuem menos de dez mil habitantes. $\mathrm{O}$ município de Tomazina, assim como no caso das taxas de homicídios, foi o que apresentou o menor valor: 0,11 quilogramas de drogas apreendidas por cem mil habitantes, o que corresponde para o caso de Tomazina, município de 8.791 habitantes (IBGE, 2010), a apreensão de dez gramas de maconha que aconteceu na cidade.

\section{Considerações finais}

A segurança pública se converteu em um dos principais temas da agenda social brasileira devido, principalmente, ao aumento significativo da violência. No campo acadêmico, é visível uma ampliação dos estudos acerca desse tema na chamada Geografia da Violência.

A violência, apesar de abordada por inúmeras perspectivas, tem presença tão corriqueira no cotidiano que parece familiar, porém é preciso considerar que é profundamente marcada pela ideologia e por uma difusão do conceito. Ao mesmo tempo que é destacada por essa variedade de olhares, é preciso buscar entendimentos sobre as especificidades das violências nas multiplicidade de espaços no Brasil. 
Assim, agruparam-se as bases teóricas em perspectivas consonantes. A primeira abordagem consiste na violência como reflexo da própria condição humana. Então, desde o processo civilizatório, a sociedade tem domesticado essa violência intrínseca do ser humano, e a materialização dela, atualmente, como os homicídios, seria um resquício daquela condição inicial violenta. A segunda perspectiva representa a violência como reflexo do modo de produção capitalista e da globalização. A terceira abordagem transita pela violência como uma perspectiva contemporânea, a partir da sociedade de classe, da ideologia do individualismo, da cultura do consumo e do cenário de esvaziamento dos valores coletivos. Na quarta perspectiva, a violência vinculada ao espaço urbano, é entendida como reflexo e condicionante do espaço urbano, como a divisão social do trabalho, as desigualdades sociais (quanto ao acesso à moradia, à educação, bem como a outros direitos sociais) e as ações do Estado.

No caso empírico, esta pesquisa focalizou a realidade da violência do Norte Pioneiro do Estado do Paraná, composto por 46 municípios e por parcela relevante de território e de população dentro do Estado paranaense. Para isso, utilizou-se dados de homicídio, considerado a violência máxima por ter como consequência o assassinato de uma pessoa, e os dados de apreensão de drogas ilícitas (maconha, cocaína e crack). A região marcada e, amplamente, reconhecida pela colonização cafeeira, vive uma epidemia de casos de homicídios. Os municípios com menores valores já experimentam uma realidade preocupante ou alarmante. Os principais motivos para esses dados são: tráfico de drogas e insuficiência dos serviços públicos de segurança. Quanto às apreensões de drogas ilícitas, os dados mostram apenas uma face do processo: a região é rota do tráfico ilícito de drogas. Já a compreensão do tráfico de drogas nas cidades precisa de mais trabalhos empíricos, sobretudo considerando que a ausência ou/insuficiência dos serviços públicos de segurança facilita o movimento do tráfico de drogas.

\section{Referências}

BAUMAN, Zygmunt. Confiança e medo na cidade. Rio de Janeiro: Zahar, 2009.

BAUMAN, Zygmunt. Tempos líquidos. Rio de Janeiro: Zahar, 2007.

BENEVIDES, Maria Victoria. Violência, povo e política. São Paulo: CEDEC/Brasiliense, 1983.

BRASIL, Constituição da República Federativa do Brasil: promulgada em 5 de outubro de 1988. $18^{a}$ edição. São Paulo: Saraiva, 1998. 
CHAUI, Marilena. Simulacro e poder. São Paulo, Editora Fundação Perseu Abramo, 2006.

ENDLICH, Angela Maria. Maringá e o tecer da rede urbana regional. Dissertação (Mestrado) - Faculdade de Ciência e Tecnologia, Universidade Estadual Paulista, Presidente Prudente, 1998. 221 p..

ENDLICH, Angela Maria. Pensando os papéis e significados das pequenas cidades do Noroeste do Paraná. 505 p. Tese (doutorado) - Universidade Estadual Paulista Faculdade de Ciências e Tecnologia. Presidente Prudente: [s.n.], 2006.

FERNANDES, Pedro Henrique Carnevalli. Um espectro ronda as pequenas cidades: o aumento da violência e da insegurança objetiva. 525 p. Tese (doutorado). Programa de Pós-Graduação em Geografia da Universidade Estadual de Maringá. Maringá, 2017.

GAVIRIA, Margarita Rosa. Controle social expresso em representações sociais de violência, insegurança e medo. Sociologias, Porto Alegre, n. 20, p. 72 a 107, jul./dez, 2008.

GOES, Eda Maria. A recusa das grades: rebeliões nos presídios paulistas: 1982-1986. São Paulo: IBCCRIM, 2009.

GOES, Eda Maria. Imagens da polícia. Relações entre cidadania e violência caracterizadas nas representações da polícia paulista: janeiro/83 - março/85. 245 p. Tese (doutorado em História), Universidade Estadual Paulista, Assis: [s.n.], 1998.

GOES, Eda Maria. Transição política e cotidiano penitenciário. História, Franca, v. 23, n.1-2, p. 219-238, 2004.

IBGE. Instituto Brasileiro de Geografia e Estatística. Censo Demográfico 2010. Rio de Janeiro: IBGE, 2010.

IBGE. Instituto Brasileiro de Geografia e Estatística. Divisão Regional do Brasil. Rio de Janeiro: IBGE, 2008.

LEFEBVRE, Henri. O direito à cidade. Tradução de Rubens Eduardo Frias. São Paulo: Centrauro, 2001.

MAGALHÃES, Nara. Significados de violência em abordagem da mensagem televisiva. In: Sociologias, Porto Alegre, n. 21, p. 318-343, jan./jun., 2009.

MOREIRA, Jacqueline de Oliveira; ABREU, Anderson Kerley Chaves de; OLIVEIRA, Marina Clemente de. Moralidade e sociabilidade em Frankl: um norte para superação da violência. Psicologia em Estudo, Maringá, v. 11, p. 627-635, 2006.

PEDRAZZINI, Yves. A violência das cidades. Tradução de Giselle Unti. Petrópolis (RJ): Vozes, 2006.

RIFIOTIS, Theophilos. Violência policial e imprensa: o caso da Favela Naval. São Paulo em perspectiva. São Paulo, v. 13, n. 4, p. 28 a 41, out./dez., 1999. 
RODRIGUES, Arlete Moysés. Geografia e Violência Urbana. In: Geografia em perspectiva. Nídia Pontuscha (org.). São Paulo: Editora Hucitec, 2002.

SILVA, Luiz Antônio Machado da. Sociabilidade violenta: por uma interpretação da criminalidade contemporânea no Brasil urbano. Sociedade e Estado, Brasília, v. 19, n. 1, p. 53-84, jan./jun, 2004.

SOUZA, Marcelo Lopes de. Fobópole: o medo generalizado e a militarização da questão urbana. Rio de Janeiro, Bertrand Brasil, 2008.

TEIXEIRA, Maria Cecília Sanches; PORTO, Maria do Rosário Silveira. Violência, insegurança e imaginário do medo. Caderno Cedes, Campinas, v. 19, n. 47, p. 51-66, dez., 1998.

VIANA, Nildo. Violência urbana: a cidade como espaço gerador de violência. Goiânia: Edições Germinal, 2002. 